\title{
Retinal vascular occlusions in open heart surgery
}

\author{
ISLA M. WILLIAMS \\ Monash University, Department of Medicine, Alfred Hospital, Victoria, Australia
}

During open heart surgery large numbers of microemboli circulate in the blood stream. Both white plugs and refractile specks have been observed in the retinal circulation (Williams, I97I). Necropsy findings (light microscopy) support the interpretation that the white plugs are formed in the blood stream from blood constituents (Williams, 197I). Emboli of platelets, of fat, and of "crystalline" material have been identified at necropsy in the brain and other organs of patients after cardiopulmonary bypass surgery (Aguilar, Gerbode, and Hill, 1971). Dogs subjected to total cardiopulmonary bypass develop retinal emboli of platelets and degenerate cellular material, of fat, and of dimethylpolysiloxane with silica gel (Williams, Farmer, and Dixon, 1974).

The present paper describes the necropsy findings in the retina of two further patients who died after open heart surgery. The white retinal vascular plugs (observed by direct ophthalmoscopy and under the dissection microscope) were examined by electron microscopy, the fat identified by a histochemical stain, and the presence of silicon in the "crystalline" emboli confirmed by electron probe $x$-ray microanalysis. Dimethylpolysiloxane fluid with silica gel (Antifoam A-Dow Corning) is used as a defoaming agent in the perfusion of patients during open heart surgery.

\section{Case reports}

Case 1, a 37-year-old Maori male, with mitral and tricuspid valve prostheses, was admitted with septicaemia due to Staphylococcus aureus and a "stuck" tricuspid valve prosthesis (that is, a valve which was fixed). At operation the surgeon found active granulation tissue covering both valve prostheses and replaced each with a Starr Edwards ball-valve prosthesis. In the extracorporeal circuit, blood was oxygenated with a bubble oxygenator and all priming blood, transfusion, and cardiotomy blood was passed through a Swank filter. The bypass time was $215 \mathrm{~min}$. ( 19 mths previously, the patient's mitral and tricuspid valves had been replaced for the first time with a Starr Edwards ball-valve prosthesis and a Starr Edwards disc prosthesis respectively. At the patient's first open heart operation blood was oxygenated with a disc oxygenator, and the bypass time was I 7 I min. No filter was used.)

Address for reprints: Isla M. Williams, Department of Medicine, Monash Medical School, Alfred Hospital, Prahran, Victoria 3181, Australia
During the second open heart operation, the patient's optic fundi were observed with a direct ophthalmoscope, the pupils having been dilated with Gyclopentolate $\mathrm{HCl}$ I per cent. and Phenylephrine $\mathrm{HGl}$ (viscous) io per cent. I hr after bypass began, a white embolus occluded a branch of the inferonasal artery in the right eye and two refractile specks appeared in the upper temporal quadrant of the right eye and one in the inferotemporal quadrant of the left eye.

Haemostasis was difficult to achieve and the patient was transfused with 31 units of blood. After the operation he remained unconscious, responding only to painful stimuli and died ro hrs, $20 \mathrm{~min}$. later.

Case 2, a 57-year-old Caucasian male, was admitted in cardiac failure with thrombosis of his mitral valve prosthesis. The surgeon replaced the valve with a Starr Edwards ball-valve prosthesis. During the operation blood was oxygenated in a bubble oxygenator and all priming blood, transfusion, and cardiotomy blood was passed through a Swank filter. A Pall filter was included on the arterial line. The bypass time was $126 \mathrm{~min}$. ( 4 yrs previously the patient's mitral valve had been replaced for the first time with a Starr Edwards ball prosthesis. During the first operation, blood was oxygenated in a bubble oxygenator and all priming blood, transfusion, and cardiotomy blood was passed through a Swank filter. The bypass time was 94 min.)

Haemostasis at the second operation was difficult to achieve and postoperatively the patient remained unconscious and unresponsive to painful stimuli. He died after $20 \mathrm{hrs}$. His fundi were not observed during the operation.

\section{Pathological data}

METHOD

At necropsy, soon after death in Case I, the globes were fixed in Hogan's fixative and opened coronally through the ora serrata. A segment of retina containing the white plug which lodged in a branch of the inferonasal artery in the right eye during operation, was excised for post-fixation in I per cent. osmium tetroxide, dehydrated in acetone, and embedded in araldite. Sections I $\mu$ thick were stained with methylene blue and safronin $O$ for examination by light microscopy. Thin sections were stained with uranyl acetate and lead citrate and examined with a Siemens electron microscope. A second white arterial plug 
detected under the dissection microscope in the peripheral part of the superotemporal quadrant of the retina was sectioned for examination in the same manner.

Several flat mounts of the retinal vessels were prepared by trypsin digestion according to the technique of Kuwabara and Cogan (1960) and stained with oil red $\mathrm{O}$, haematoxylin and eosin ( $\mathrm{H}$ and $\mathrm{E})$, periodic acid-Schiff reagent counterstained with haematoxylin (PAS), and Schultz stain for cholesterol. The vessels were examined under the light microscope with transmitted light and with phase contrast microscopy. Retinal vessels prepared by trypsin digestion were mounted on an aluminium block and coated with $200 \AA$ thick evaporated film of conducting carbon for examination with the electron probe (Cambridge Microscan 5). Back scattered electron and corresponding silicon $x$-ray distribution images were recorded photographically from the cathode ray screen.

At necropsy in Case 2, Io hrs after death, the posterior poles of the globes were excised through the supraorbital plate of each orbit and fixed in Hogan's fixative. Unfortunately, folding of the retina prevented a complete examination. A segment of retina containing a vessel with a white mass indistinguishable under the dissection microscope from the white plugs in Case I, was excised and prepared for examination as in Case I. Trypsin digest flat mounts of the retinal vessels were prepared. Some were stained for examination by light microscopy and others mounted on an aluminium block and examined with the electron probe as in Case I.

\section{RESULTS}

White retinal vascular occlusions visible with the direct ophthalmoscope and dissection microscope

In Case I, light microscopical examination showed that each white retinal arterial plug comprised granular material and a few leucocytes and red cells. Fig. I $a$ shows in section the white arterial plug excised from the superotemporal quadrant of the retina of the right eye. The electron micrograph of this plug shows platelets and red cells trapped in a loose mesh of fibrin with occasional leucocytes at the periphery (Fig. $1 b$ ). The white plug observed during surgery in the inferonasal artery of the patient's right eye comprised mainly platelets and fibrin (Fig. 2).

Fig. $3 a, b$ shows in section the vessel containing the white mass excised from the retina in Case 2. The lumen-a slim opening lined by endothelium (Fig. 3c)-contained red cells in some sections. The endothelial cells were surrounded by a thin basement membrane and occasional pericytes. Collagen with some unorganized amorphous material lay deep to these layers and occupied the greater part of the

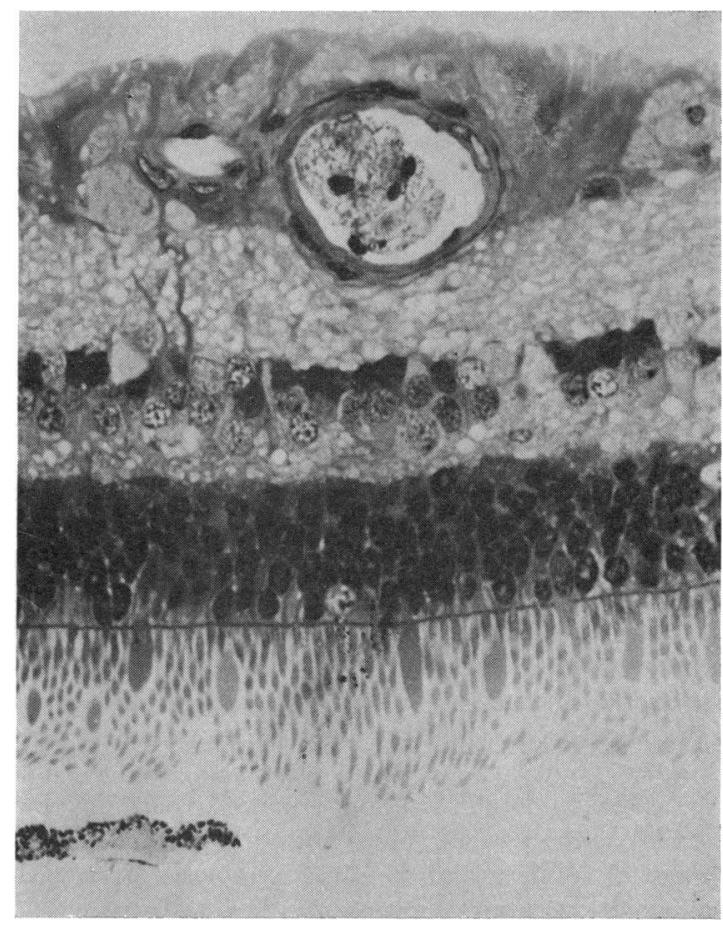

FIG. I Case I. Microthrombotic retinal arterial embolus detected at necropsy after open heart surgery.

(a) Section of retina, showing arterial embolus. Methylene blue and safronin O. $\times 64$

section. Fig. $3^{d}$ shows the loosely arranged collagen fibres which surrounded the entire vessel. The densely packed collagen is also shown in Fig. $3 d$ and in higher power in Fig. $3 e$.

Fat occlusions visible in retinal vessels prepared by trypsin digestion and examined under the light microscope

The retinal vessels prepared by trypsin digestion in both Case I and Case 2 contained occlusions staining bright red with oil red $\mathrm{O}$ (Fig. 4) which were interpreted as fat. The oil red $O$ positive material coated red cells and mingled with faintly pink-staining "crystalline-like" material interpreted as dimethylpolysiloxane with silica (Antifoam A-Dow Corning).

Occlusions of dimethylpolysiloxane with slica (Antifoam A) visible in retinal vessels prepared by trypsin digestion and examined under the light microscope

The retinal vessels prepared by trypsin digestion in both Case $I$ and Case 2 contained occlusions which stained faintly pink with oil red $\mathrm{O}$ (Fig. 5a) and had star-like pink clusters (crystals of oil red $\mathrm{O}$ ), but failed to stain with $\mathrm{H}$ and E, PAS, or Schultz stain. Phase 


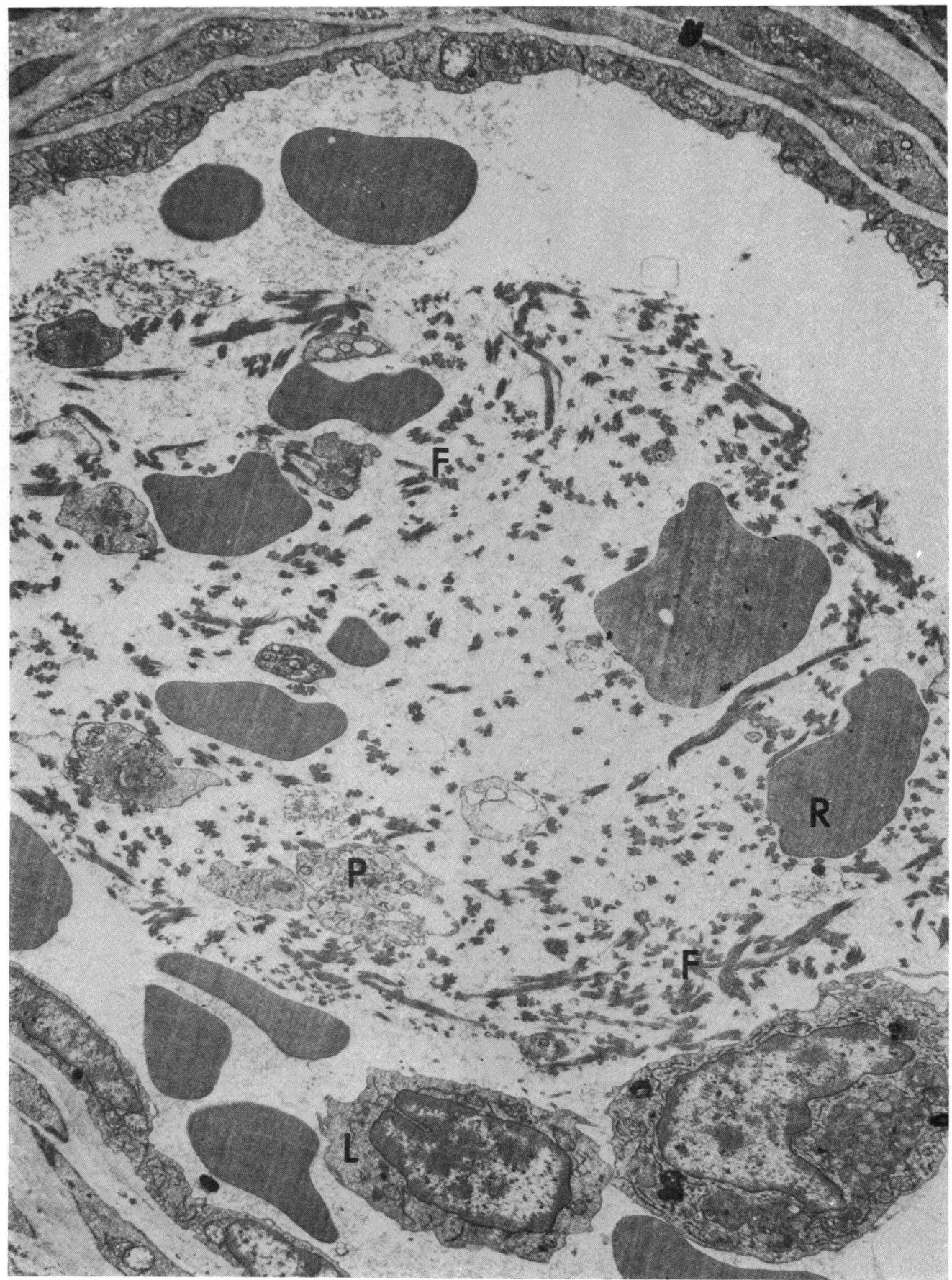

FIG. I (b) Electron micrograph of arterial embolus showing platelets $(\mathbf{P})$ and red cells $(\mathbf{R})$ enmeshed in fibrin (F) and two leucocytes (L) at the periphery of the plug. $\times 5,000$ 

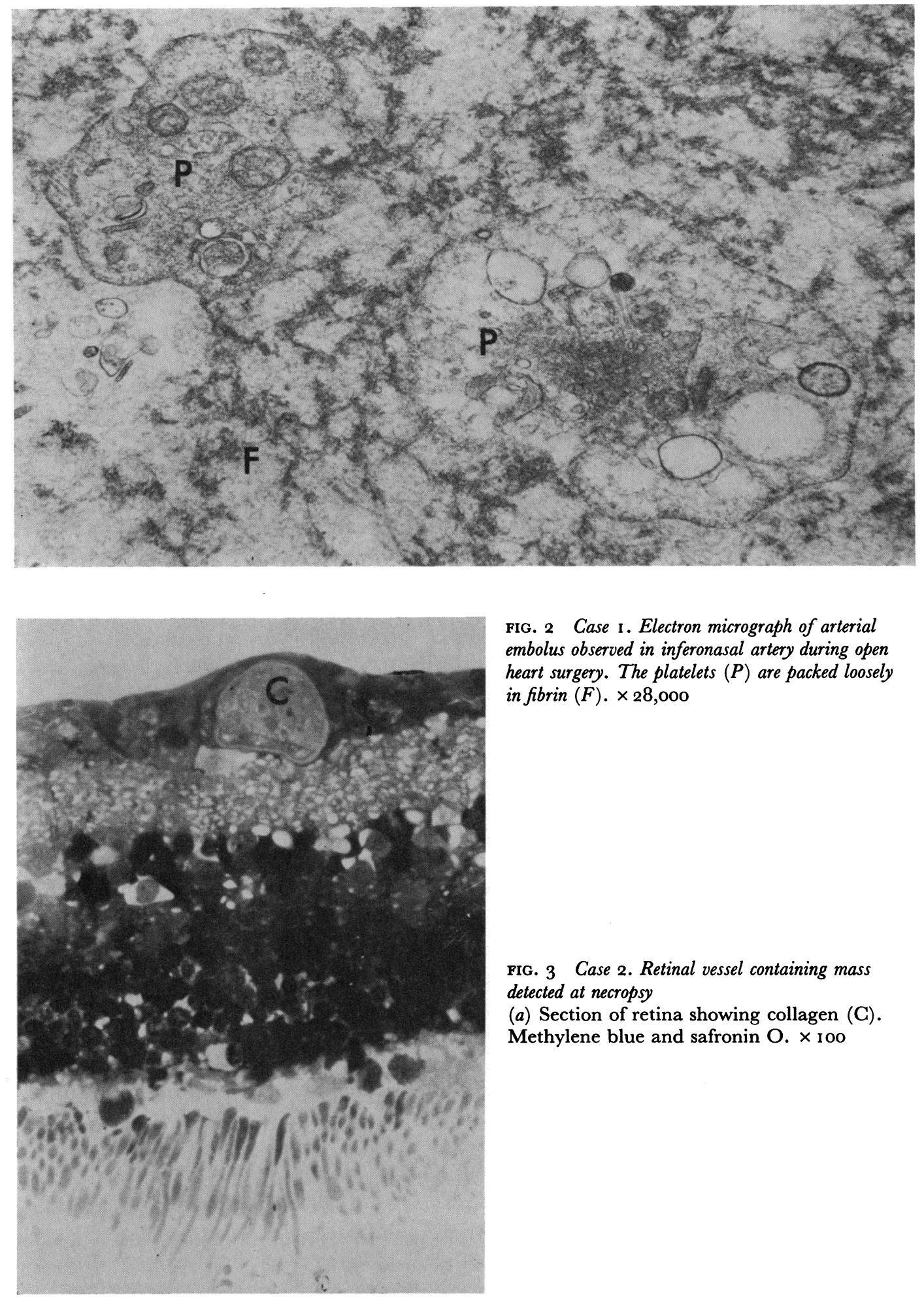

FIG. 2 Case I. Electron micrograph of arterial embolus observed in inferonasal artery during open heart surgery. The platelets $(P)$ are packed loosely in fibrin $(F) . \times 28,000$

FIG. 3 Case 2. Retinal vessel containing mass detected at necropsy

(a) Section of retina showing collagen (C). Methylene blue and safronin $\mathrm{O} . \times$ Ioo 


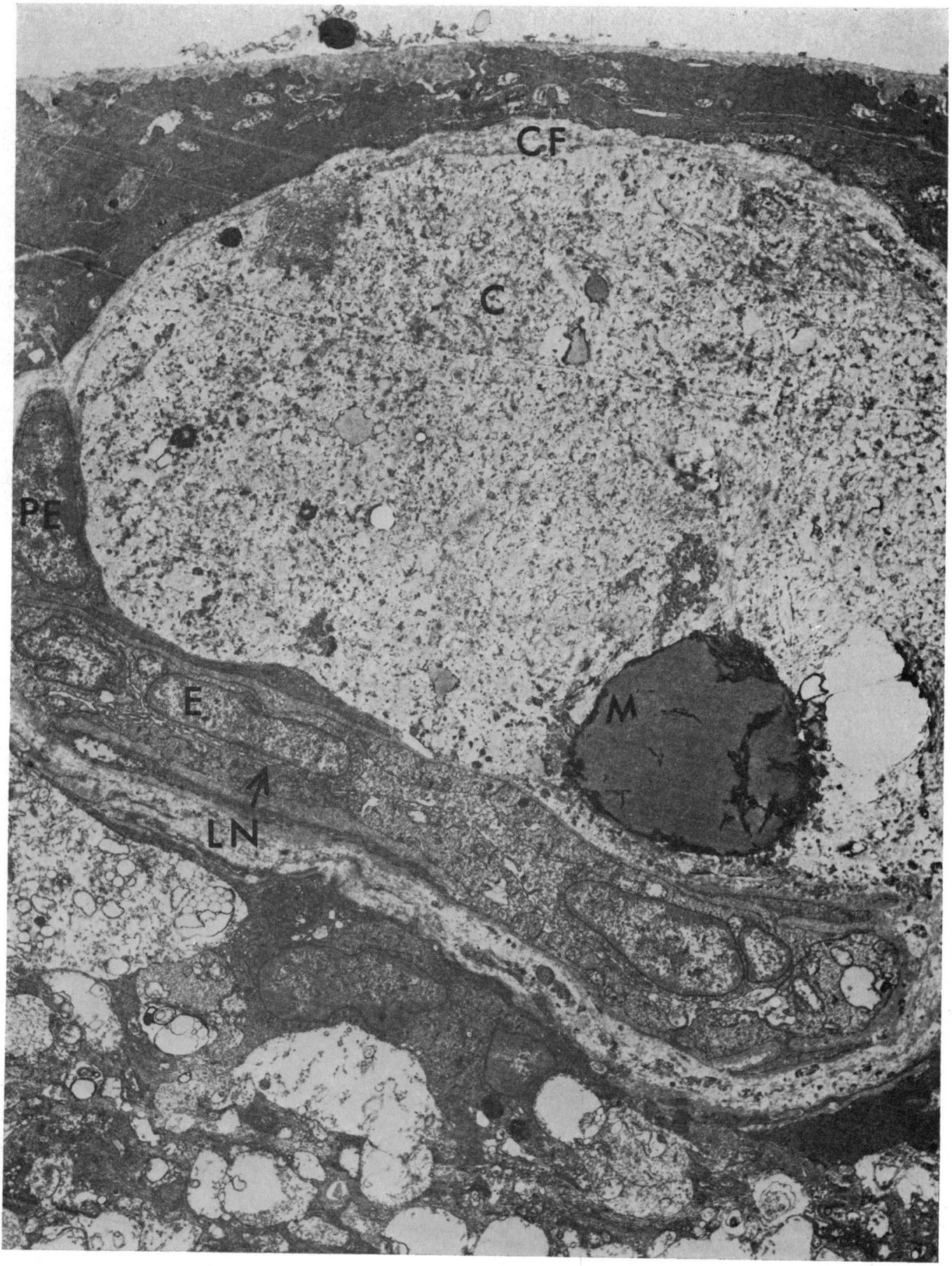

FIG. 3 (b) Electron micrograph of retinal vessel showing collagen $(\mathrm{C})$ and unorganized amorphous material (M) lying outside the lumen (LN) (lined by endothelial cells (E) and pericytes (PE)) bur inside the band of loosely arranged collagen fibres (CF) which form the outerwall of the vessel. $\times 5,000$ 


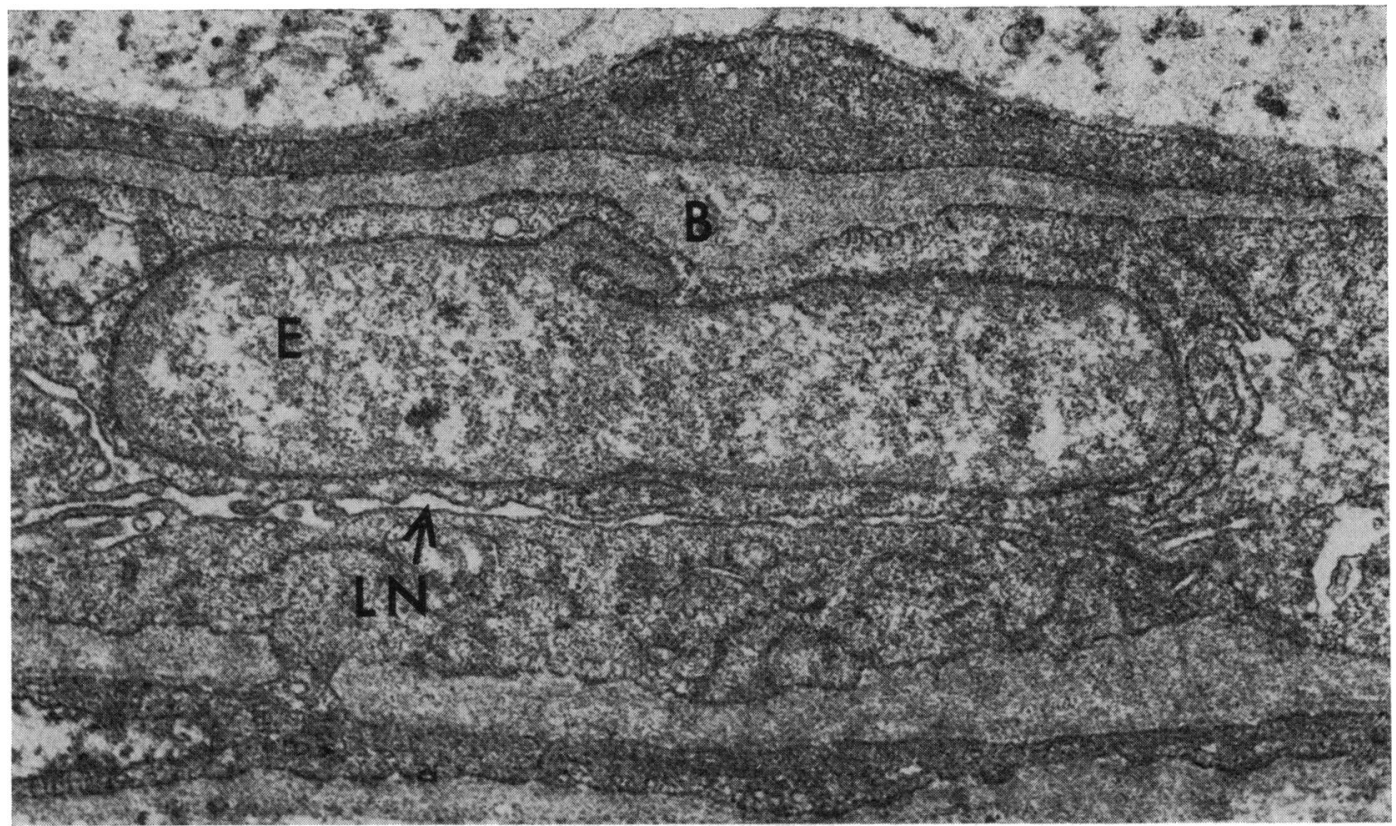

FIG. $3(c)$ Electron micrograph of lumen $(\mathrm{LN})$ of retinal vessel. $\mathrm{E}=$ endothelial cell. $\mathrm{B}=$ basement membrane. $\times$ I 7,000

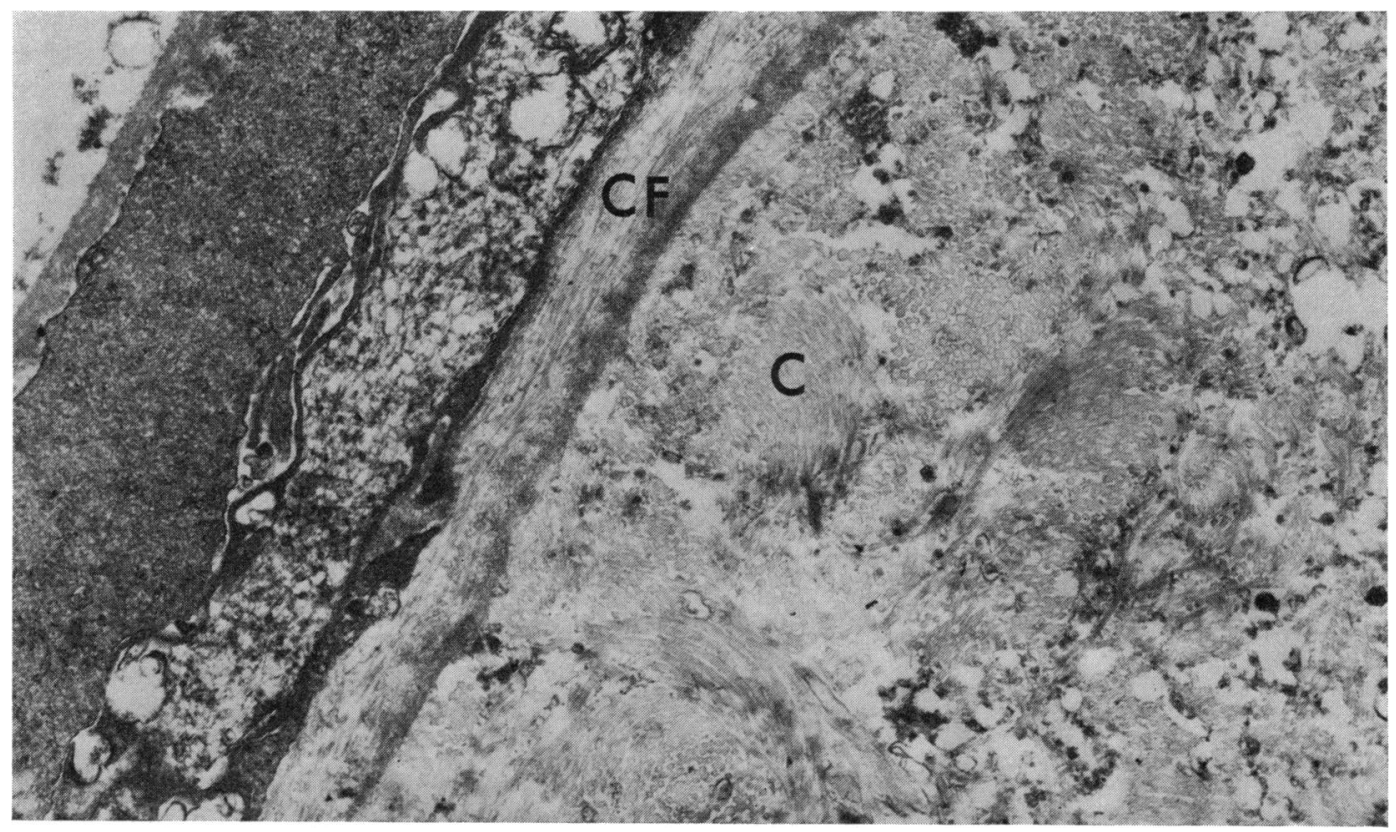

FIG. $3(d)$ Electron micrograph, showing mature collagen mass $(C)$ and loosely arranged collagen fibres $(\mathrm{CF})$ in higher power. $\times 20,520$ 


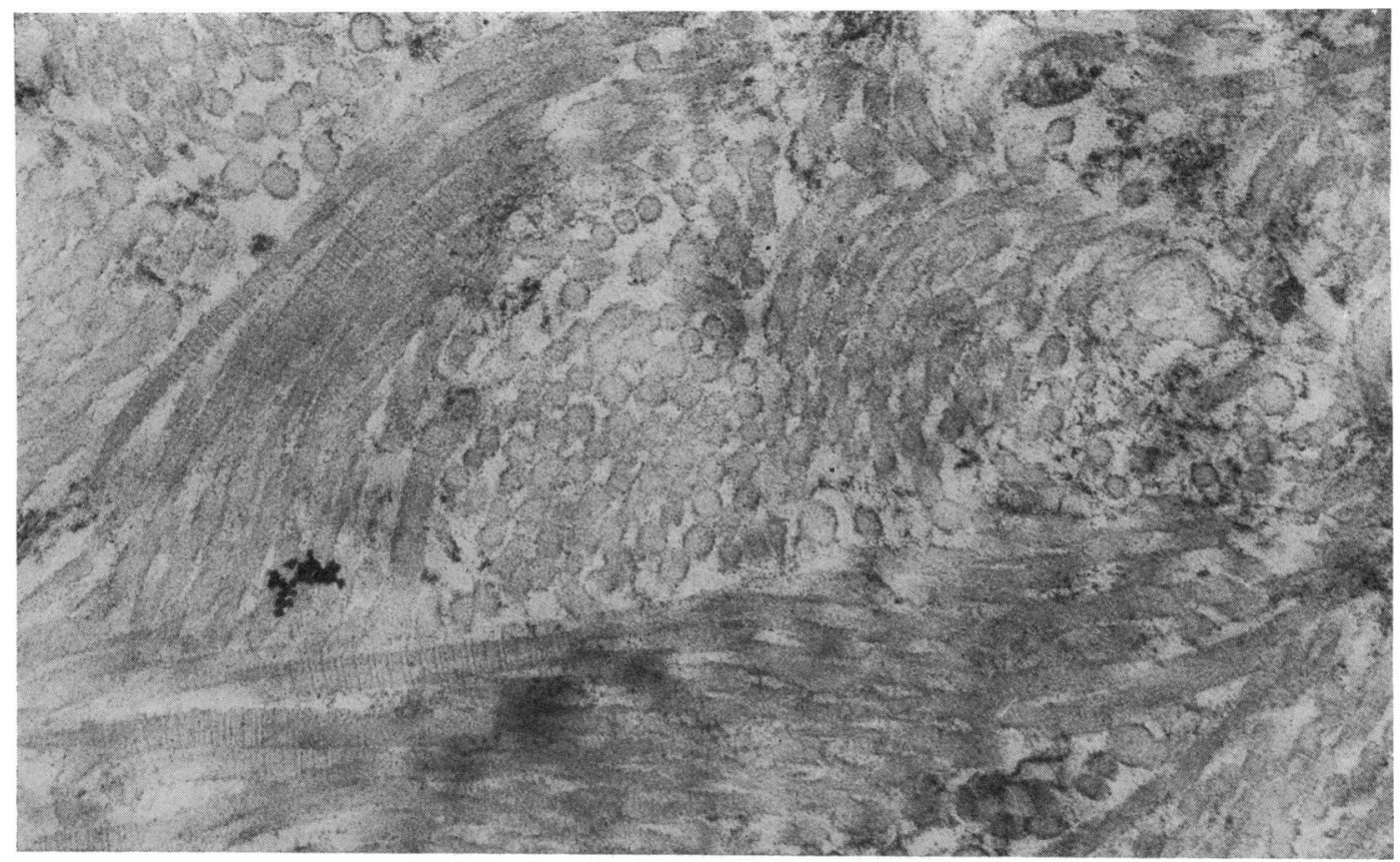

FIG. $3(e)$ Electron micrograph, showing mature collagen mass. $\times 75,000$

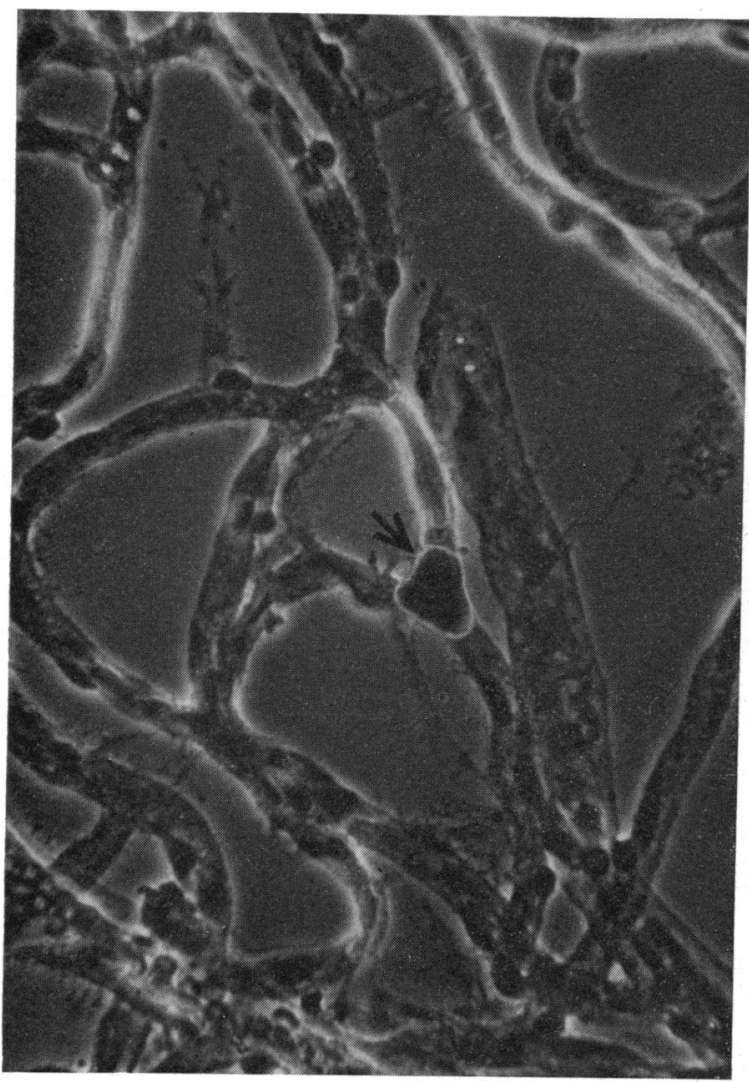

FIG. 4 Case I. Retinal capillary occlusion of fat demonstrated in trypsin digest preparation after open heart surgery. Oil red O. $\times 256$ 
contrast microscopy showed that, in some areas, the colourless material was coarsely granulated. The vessels containing such occlusions were distended, whilst adjacent to such occlusions the vessels were constricted about masses of blood cells (Fig. $5 b$ ). In some areas the colourless occlusions were finely granular and distended capillaries which had lost their nuclei (Fig. $5 c$ ); the finely granular material was sometimes extruded from the vessel in the presence of a histiocyte (Fig. $5 d$ ).

Examination with the electron probe disclosed a high content of silicon in several discrete areas of the retinal capillary network prepared by trypsin digestion in both Case $\mathrm{I}$ and Case 2. $\mathrm{Fe}, \mathrm{Mn}, \mathrm{Ti}$, $\mathrm{Ca}, \mathrm{Mg}, \mathrm{Na}$, and $\mathrm{Al}$ were sought in the siliconrich areas but were not found in either case.

FIG. 5 Case I. Retinal capillary occlusions of dimethylpolysiloxane with silica demonstrated in trypsin digest preparations

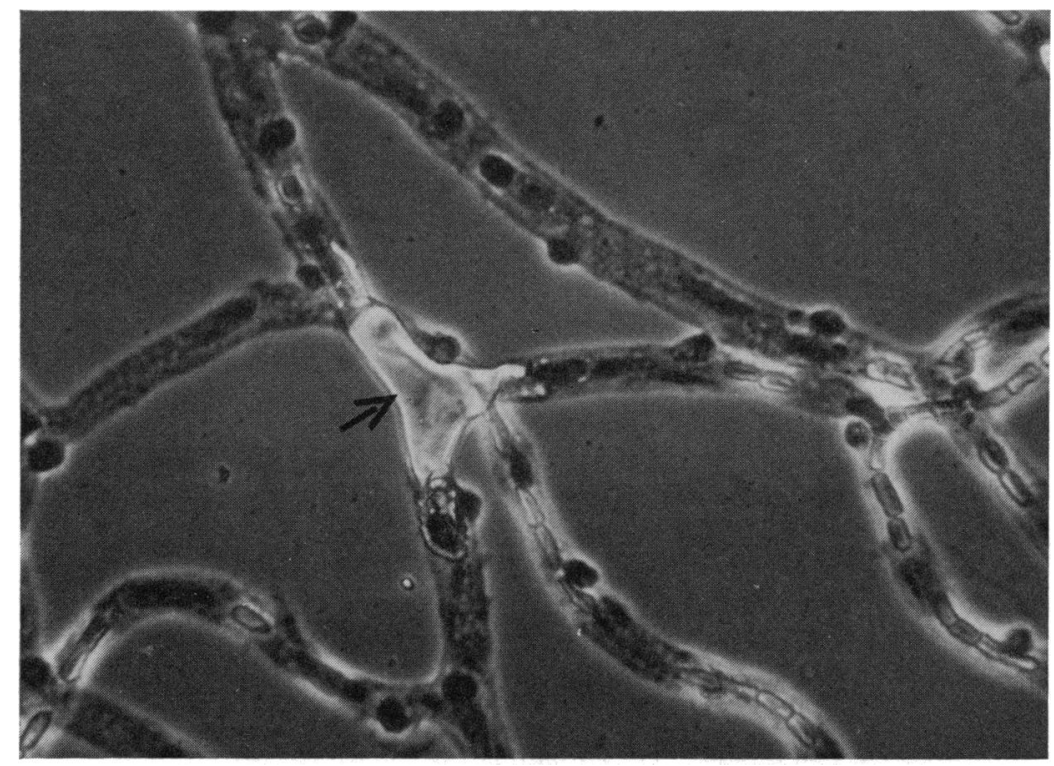

(a) Faintly pink occlusion.

Oil red O. $\times 256$

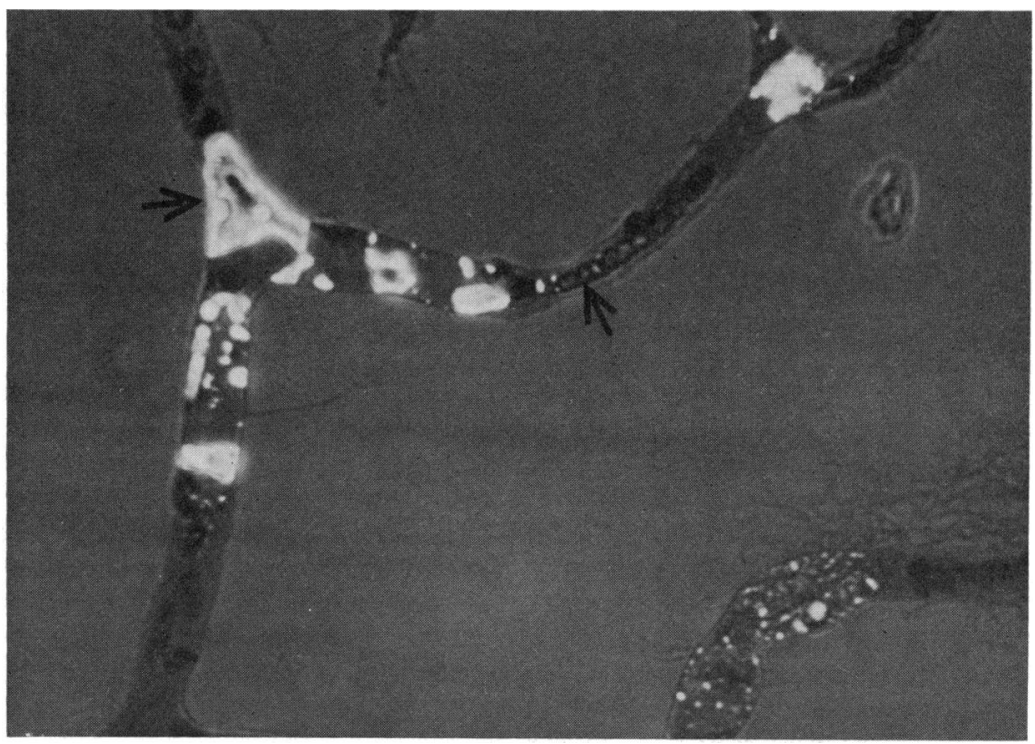

(b) Phase contrast microscopy shows coarsely granular material distending a retinal capillary; adjacent, the capillary containing red cells is narrow. Haematoxylin and eosin. $\times 256$ 


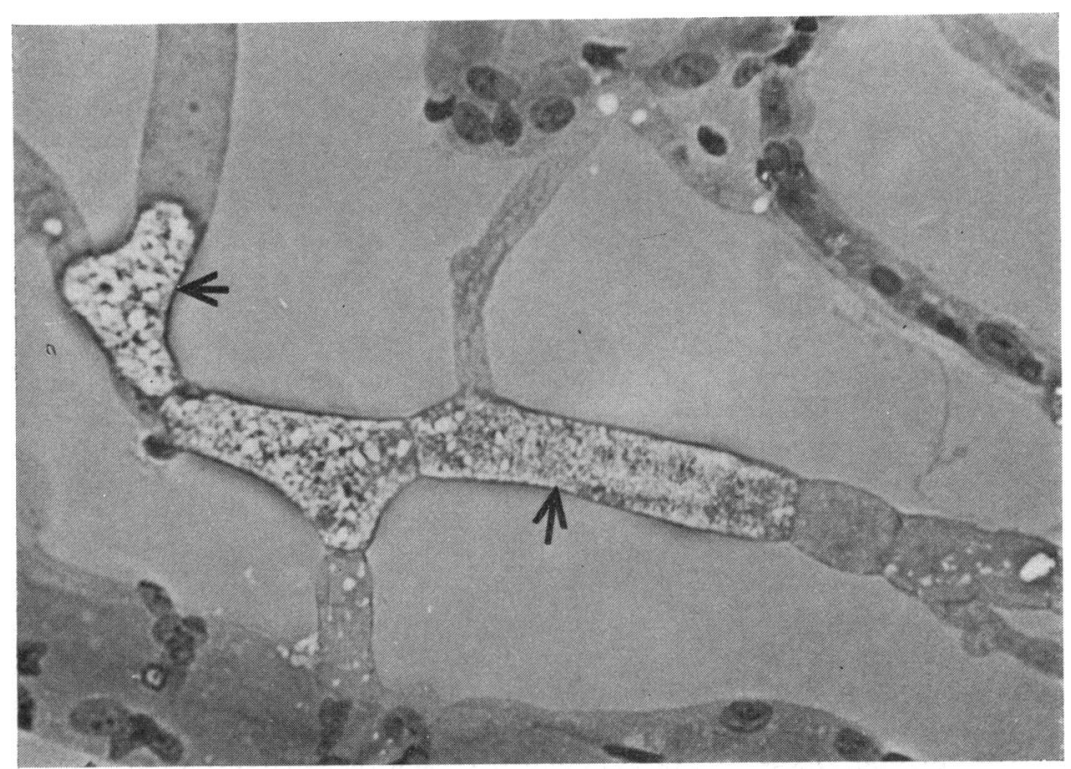

FIG. 5 (c) Phase contrast microscopy shows finely granular material distending capillaries which have lost their nuclei. Periodic acid-Schiff reagent counterstained with haematoxylin. $\times 256$

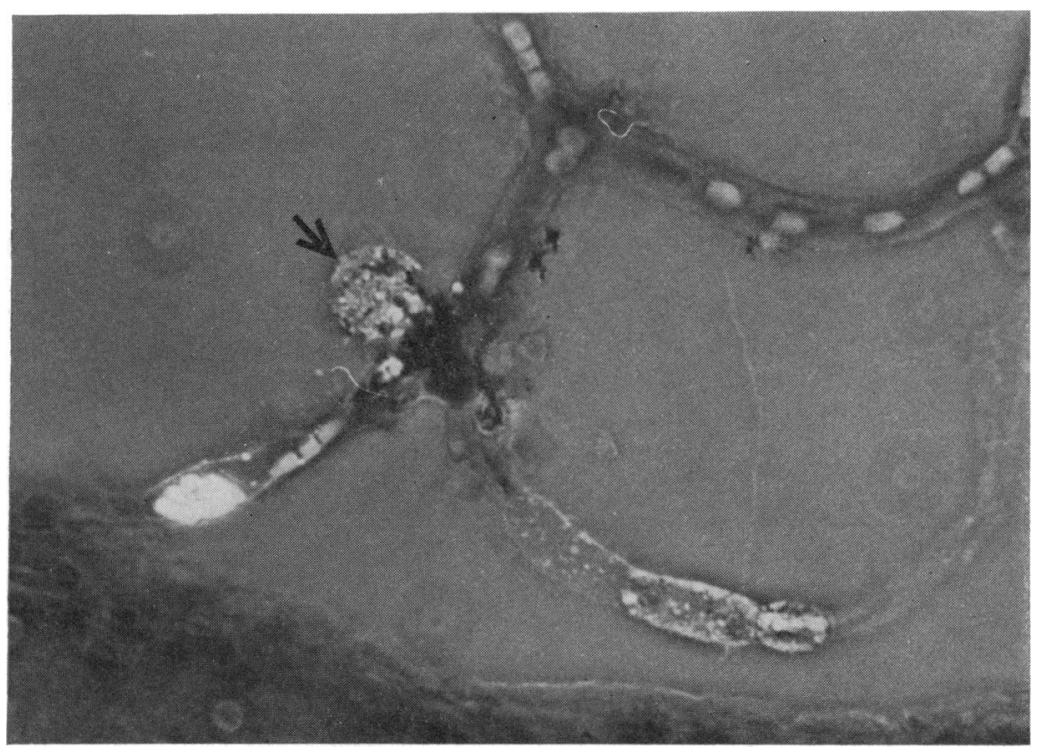

FIG. $5(d)$ Phase contrast microscopy shows finely granular material extruded from a capillary in the presence of a histiocyte. Periodic acid-Schiff reagent counterstained with haematoxylin. $\times 256$

\section{Discussion}

A study of the retinal vasculature offers a unique opportunity to examine microvascular occlusions in man. In previous studies in man, white plugs observed in retinal vessels by direct ophthalmoscopy during open heart surgery and examined at necropsy under the light microscope were interpreted as platelet occlusions (Williams, 1971). The ultrastructure of one white plug observed in the retinal circulation during open heart surgery in Case $\mathrm{I}$ in this study confirms the interpretation that white plugs contain platelets (Fig. 2) and other blood cells. The ultrastructure of the white plugs in Case I was similar to that of white plugs found in the retinal circulation of dogs after cardiopulmonary bypass surgery (Williams and others, 1974).

Many mechanisms contribute to the formation of platelet aggregates (Mustard, 1969). In open heart surgery, embolism has been proposed as a major source of morbidity (Osborn, Swank, Hill, Aguilar, and Gerbode, 1970). In modern open heart surgery, 
filters remove platelet aggregates but fail to remove emboli of fat and of Antifoam A (Williams and Davis, 1973). Since the introduction of filters more patients regain consciousness quickly and postoperative confusion is less (Swank and Osborn, I 970). Furthermore, platelet emboli observed in the retinal circulation during cardiopulmonary bypass procedures occur principally in those patients who develop neurological complications and in those who fail to survive (Williams, r973). These observations are consistent with those of Jørgensen ( 1969 ), who stated that platelet aggregates in flowing blood, even when only transient, may have serious effects on organ structure and function.

Intense injury of a vessel wall by any means precipitates the formation of a thrombus consisting primarily of platelets at the site of injury (Berman, I969). The white retinal plug observed during open heart surgery in Case $I$ in this study contained mainly loosely packed platelets (Fig. 2) and may have originated from an injured vessel wall, although other factors may have contributed to its formation. Stasis favours the formation of loosely-packed fibrin clots (Berman, ig69).

Fibrin thrombi are always small and occur almost exclusively in small vessels. The few platelets in these thrombi appear to be trapped (Chandler, r969). The thrombus excised from the peripheral retina contained mainly loosely-packed fibrin in which were enmeshed a few platelets and red cells. It is suggested this thrombus formed during the period of 10 hours or more of sluggish circulation before death in Case I.

The white mass in the retinal vessel in Case 2, though similar in appearance under the dissection microscope to the white occlusions in Case I, was found to comprise mainly collagen deep to the endothelial lining of the vessel which was patent. Friedenwald, Wilder, Maumenee, Sanders, Keyes, Hogan, Owens, and Owens (1952) observed in small retinal arteries subendothelial fibrotic plaques with the appearance ophthalmoscopically of a localized irregular whitish sheath surrounding the arterial blood column, and pointed out their close similarity to thickenings in walls of veins, which consisted of proliferated masses of cells in and under the venous endothelium. In Case 2 the collagen mass may have developed by fibrosis of such a mass of cells in the wall of a vein.

On the other hand, the collagen mass may represent an organized embolus of blood constituents. This patient had been exposed to circulating emboli during two open heart operations and had had a mitral valve prosthesis for 4 years. Jørgensen, Hovig, Rowsell, and Mustard (1970) concluded that transient platelet aggregation in the microcirculation may be an important factor in causing vascular occlusions and mural thrombosis. Furthermore, Jørgensen and Torvik (1969) found that venous platelet aggregates were prevalent among patients with occluded arteries supplying the brain, particularly when those occlusions were due to grossly visible emboli from the heart and other intrathoracic sources. It is suggested a venous platelet aggregate, formed in the flowing blood, damaged and adhered to the vessel wall, giving rise to a sessile mural thrombus. Subsequently, the thrombus organized and the endothelium was reconstituted over it. Such an initial venous aggregate must have formed before the second open heart operation, because the endothelium of the vessel was intact in each section made and the collagen was mature. The area of unorganized amorphous material in the fibrous mass is consistent with this being an organized mural thrombus (French, I962).

Emboli of fat and of "crystalline" material have been identified at necropsy in the brain and other organs of patients after total cardiopulmonary bypass (Aguilar and others, I97 I). Trypsin digest flat mounts of retinal vessels allow the morphology of whole microemboli to be studied. In the retinal vessels of Case I and Case 2, oil red $O$ positive material. interpreted as fat, was found in discrete globules, coating red cells, and mixed with "crystalline-like" occlusions.

Thomassen, Howbert, Winn, and Thompson (I96I) found an intravascular foreign material in the tissues of patients exposed to a silicone defoaming agent during extracorporeal circulation. They presented evidence that the foreign material was particulate matter present in the antifoaming agent. The colourless occlusions ( $\mathrm{H}$ and $\mathrm{E}$ and PAS) and faintly pink occlusions with star-like pink clusters (oil red $\mathrm{O}$ ) found in the retinal capillaries in Case 1 and Case 2 were indistinguishable from retinal capillary occlusions found in the dog after cardiopulmonary bypass procedures (Williams and others, I974) where $\mathrm{Hi}$ Vacuum Grease, similar in composition to Antifoam A, was used in the disc oxygenator. Furthermore, the retinal capillary occlusions produced by the intracarotid injection of both Antifoam $A$ and of Hi Vacuum Grease appeared similar with identical stains, and closely resembled globules of Antifoam A and of $\mathrm{Hi}$ Vacuum Grease which were smeared on microscope slides and stained in the same way (Williams and others, 1974).

In the retinal capillaries prepared by trypsin digestion in Case I and Case 2, a high content of silicon was located in several areas with the electron probe, which is consistent with the interpretation that the "crystalline-like" occlusions were dimethylpolysiloxane with silica gel.

Phase contrast microscopy demonstrated the microvascular occlusions of dimethylpolysiloxane with silica gel in retinal capillaries prepared by trypsin digestion in Case $I$ and Case 2 to be sometimes finely granular and sometimes coarsely granular. 
Both patients had undergone a previous open heart operation in which dimethylpolysiloxane with silica was used as the defoaming agent and for which there is no known method of excretion. Finely granular occlusions were not found in the retinal capillaries of dogs after cardiopulmonary bypass surgery (Williams and others, 1974). It is suggested the finely granular occlusions were dimethylpolysiloxane fluid with silica which had been present since the first operation in Case I and Case 2. Furthermore, the retinal capillaries containing finely granular occlusions had lost their nuclei and in some areas the finely granular material had been extruded from the capillary in the presence of a histiocyte. Death of capillaries and a histiocytic response were not found in the retinal capillaries of dogs after cardiopulmonary bypass surgery (Williams and others, 1974).

The refractile embolic specks observed more frequently than white platelet emboli in the retinal circulation of man during open heart surgery (Williams, 1973) may be relatively large capillary occlusions of dimethylpolysiloxane fluid with silica. However, the abundant retinal capillary occlusions of dimethylpolysiloxane fluid with silica, found in Case I at necropsy, were not visible with the direct ophthalmoscope.

\section{Summary}

This study describes microthrombotic emboli (with their ultrastructure) and emboli of fat and of dimethylpolysiloxane with silica in the retinal microcirculation of two patients who died-each after his second open heart operation. The presence of silica was confirmed by electron probe $x$-ray micro-analysis.

My thanks are due to Mr. George Stirling, Director, and members of the G.J. Officer Brown Cardiac Surgery Unit of the Alfred Hospital, to Prof. Barry Firkin, Prof. David G. Gogan, to Prof. Toichiro Kuwabara, Dr. C.H. Greer, and Dr. S. Glifton to whom I am indebted for advice on pathology, to Messrs. Stephens and Brunckhorst, who performed the electron probe $x$-ray microanalysis, and to Miss Sue Farmer and Miss Sieglinde Hohmann for their expert technical assistance in the electron microscopic studies.

The research was supported by the National Health and Medical Research Council of Australia, the Van Gleef Foundation and the Alfred Hospital Research Scholarship Fund.

\section{References}

AgUilAR, M. J., Gerbode, F., and Hill, J. D. (I97I) J. thorac. cardiovasc. Surg., 61, 676

BERMAN, H. J. (1969) In "Thrombosis", ed. S. SHERRY, K. M. BRINKHous, E. GENTON, and J. M. STENGLE, p. 537. National Academy of Sciences, Washington

CHANDLER, A. B. (I969) Idem, p. 279

FRENCH, J. E. (I962) In “General Pathology”, ed. H. Florey, 3rd ed., p. 244. Lloyd-Luke, London

FRIEDENWALD, J. S., WILDER, H. C., MAUMENEe, A. E., SANDERS, T. E., KEYES, J. E. L., hogAN, M. J., OWENS, W. C., and owens, E. U. (1952) 'Ophthalmic Pathology", p. 3 r 3. Saunders, Philadelphia

JøRGENSEN, L. (I969) In “Thrombosis", ed. S. SHERRY, K. M. BRINKHOUs, E. GENTON, and J. M. STENGLE, p. 525. National Academy of Sciences, Washington

-—, hovig, t., Rowsell, H. C., and mustard, J. F. (i970) Amer. F. Path., 6i, i6 I

- and TORVIK, A. (1969) 7. neurol. Sci., 9, 285

kuWabara, T., and cogan, D. G. (1960) A.M.A. Arch. Ophthal., 64, 904

MUSTARD, J. F. (I I69) In "Thrombosis", ed. s. SHERRY, K. M. BRINKHOUS, E. GeNTON, and J. M. STENGLE, p. 496.

National Academy of Sciences, Washington

OSBORN, J. J., SWANK, R. L., Hill, J. D., Aguilar, M. J., and Gerbode, F. (1970) 7 . thorac. cardiovasc. Surg., 6o, 575 SWANK, R. L., and OSBORN, J. (1970 In "Microcirculatory Approaches to Current Therapeutic Problems,

6th Europ. Conf. Microcirculation, Aalborg”, ed. J. DITzEL, and D. LEwis, p. 59. Karger, Basel

THOMASSEN, R. W., HOWBeRT, J. P., WINN, D. F., JR., and THOMPSON, S. W. (196I) J. thorac. cardiovasc. Surg., 41, 6I I

WILliams, I. м. (I97 I) Lancet, 2, 688

(1973) Proc. Aust. Ass. Neurol., ro, I

and DAvis, B. B. (1973) Proc. Aust. Soc. med. Res., 3, 124

, FARMer, s., and Dixon, J. (I974) v. Graefes Arch. klin. exp. Ophthal., 189, 25 I 